\title{
Whole Genome Comparative Genomic Hybridization of Ewing Sarcoma Indicates Cytoskeleton, Migration and Protein Trafficking ${ }^{+}$
}

\author{
Burçin Baran 1, Safiye Aktaş 1,*, Hülya Tosun 1,2, Gülden Diniz 1,2, Yasemin Çakır 1,2, \\ Tekincan Çağrı Aktaş ${ }^{1}$, Zekiye Altun ${ }^{1}$ and Nur Olgun ${ }^{1}$ \\ 1 Institute of Oncology, Dokuz Eylul University, Izmir 35340, Turkey; burcinbrn@gmail.com (B.B.); \\ drhulyatosun@gmail.com (H.T.); agdiniz@gmail.com (G.D.); yasemin.cakir@gmail.com (Y.Ç.); \\ tekincanaktas@yahoo.com (T.Ç.A.); zekiyesaltun@gmail.com (Z.A.); nur.olgun@deu.edu.tr (N.O.) \\ 2 Dr.Behcet Uz Children's Research Hospital, Izmir 35210, Turkey \\ * Correspondence: safiyeaktas@gmail.com \\ † Presented at the 2nd International Cell Death Research Congress, Izmir, Turkey, 1-4 November 2018. \\ Published: 5 December 2018
}

\begin{abstract}
Ewing sarcoma is a bone and soft tissue tumor either neuroectodermal or mesenchymal originated and affecting children and adolescents. In the present study, we aimed to find out prognostic and predictive biomarkers for Ewing sarcoma. Hence, we examined the copy number alterations (and related possible genes) among ten Ewing sarcoma patient samples and possible associations with the clinical outcome. DNA extraction from formalin fixed paraffin embedded archive tissues was performed. Whole genome Comparative Genomic Hybridization (CGH) was performed by NimbleGen and recorded as single Panel Rainbow through chromosomes 1-22, X and Y. Data was interpreted by SignalMap software and genetic regions matching the deletion or amplification loci were recorded. The mean age of the patients was 8.6 years. Three of the cases were male, while seven were female. According to CGH analysis, the most common DNA copy number alterations were found in SLIT-ROBO Rho GTPase activating protein (srGAP2), RANBP2 like GRIP domain (RGPD5), nephrocystin 1 (NPHP1), GTF2I repeat domain containing 2 (GTF2IRD2), pyridoxal dependent decarboxylase domain containing 1 (PXDC1), which were found downregulated among 7 of 10 patients. In conclusion, in our dataset the copy number alterations are mostly found in genes related with cytoskeletal elements, migration and protein trafficking among our patient group. Gene functional studies are required for better understanding the role of these genes in Ewing Sarcoma pathogenesis
\end{abstract}

Keywords: Ewing sarcoma; CGH array; chromosomal copy number alterations

\section{Introduction}

Ewing sarcoma is a bone and soft tissue tumor either neuroectodermal or mesenchymal originated and affecting children and adolescents [1]. About 20-25\%, cases are metastatic at the diagnosis and long-term survival are poor for metastatic or relapsed patients [1]. The diagnosis of tumor is based on small round blue cell tumor, which is stained by CD99 [2]. In addition, most of the cases have translocation between $\mathrm{t}(11 ; 22)(\mathrm{q} 24 ; \mathrm{q} 12)$ in which amino terminus of EWSR1 gene and carboxyl terminus of FLI1 gene [3]. The fusion gene leads to oncogenic activation, epigenetic remodeling. There are also other type of translocations such as $t(21 ; 22)$ (q22; q12) EWS-ERF fusion in less amount of cases [3]. In previous studies STAG2, CDKN2A, TP53 mutations were found in Ewing Sarcoma patients [4]. 
Microarray based comparative genomic hybridization are used for screening submicroscopic DNA changes between tumor and reference DNAs and detecting gains and losses between DNAs [5]. In our study, we have applied CGH technology for detecting copy number variation among Ewing Sarcoma patients and examined the genomic changes.

\section{Materials and Methods}

Total 10 Ewing sarcoma patient samples were collected between 1998-2011, from archives of Behcet Uz Pediatric Hospital, Izmir Turkey. DNA isolation was made from FFPE tissue samples. Roche Nimble Gen Comparative Genomic Hybridization array was used for detecting copy number alterations. The patients' DNA and normal control DNA (Human Genomic DNA) were labelled with Cy 3 and Cy5 each through a random priming method, using Panel Rainbow through chromosomes 1-22, X and Y. (NimbleGen Dual-Color DNA Labeling Kit, Roche NimbleGen, Inc., Madison, WI, USA). Array hybridization and washing steps were executed on NimbleGen 135K CGX-3 Array according to manufacturer's instructions. The results were analyzed with using Signal Map Software (Roche Nimble Inc., Madison, WI, USA). The aberrations in DNA copy number were detected. The study was approved from Dr.Behcet Uz Children's Research Hospital Ethical committee.

\section{Results}

Properties of Cases: Totally 10 Ewing sarcoma patients were analyzed in which three of them male and seven of them female. The mean age of the patients was 8.6 years. The oldest patient was 14 years old while the youngest was one year old. The tumors were located in different body parts (Table 1).

Table 1. Clinical features of each patient.

\begin{tabular}{cc}
\hline Patients & Clinical Features \\
\hline 1A1 & 4 years, female, spinal area \\
1A3 & 11 years, male, right thorax \\
1A5 & 1 year, male, pre-sacral \\
1A7 & 14 years, female, lower extremity \\
1A8 & 13 years, female, spinal area \\
1A12 & 7 years, female, thorax wall \\
2A1 & 13 years, male, abdominal wall \\
2A4 & 4 years, male, shoulder \\
2A5 & 8 years, female, left pleura \\
2A6 & 11 years, female, abdominal wall \\
\hline
\end{tabular}

CGH Anaysis Results: According to CGH analysis, the most common DNA copy number alterations were found in SLIT-ROBO Rho GTPase activating protein (srGAP2), RANBP2 like GRIP domain (RGPD5), nephrocystin 1 (NPHP1), GTF2I repeat domain containing 2 (GTF2IRD2), pyridoxial dependent decarboxylase domain containing 1 (PXDC1), which were found downregulated among 7 of 10 patients. This was followed by MALL, Ankyrin Repeat Domain 30A (ANKRD30A) and protein tyrosine phosphatase non receptor type 20 (PTPN20) and ubiquitin specific peptidase 22 (USP22), transmembrane phosphatase with tensin homology (TPTE), which were found in 6 of 10 patients (Table 2). 
Table 2. The most common DNA copy number aberration and corresponding gene.

\begin{tabular}{|c|c|c|c|c|c|c|c|c|c|c|c|c|c|}
\hline Symbol & Gene Name & Location & 1A1 & 1A3 & 1A5 & 1A7 & 1A8 & 1A12 & 2A1 & $2 \mathrm{~A} 4$ & 2A5 & $2 \mathrm{~A} 6$ & Total \\
\hline srGAP2 & $\begin{array}{c}\text { SLIT-ROBO Rho } \\
\text { GTPase-activating } \\
\text { protein } 2\end{array}$ & $\underline{1 q 32.1}$ & del & del & del & del & del & $\mathrm{x}$ & del & del & $\mathrm{x}$ & $\mathrm{x}$ & $7 / 10$ \\
\hline RGPD5 & $\begin{array}{l}\text { RANBP2-like and GRIP } \\
\text { domain containing } 5\end{array}$ & $\underline{2 q 13}$ & del & del & $\mathrm{x}$ & & del & del & del & del & del & $\mathrm{x}$ & $7 / 10$ \\
\hline NPHP1 & nephrocystin 1 & $\underline{2 q 13}$ & del & $\mathrm{x}$ & $\mathrm{x}$ & del & del & del & del & del & del & $\mathrm{x}$ & $7 / 10$ \\
\hline GTF2IRD2 & $\begin{array}{l}\text { GTF2I repeat domain } \\
\text { containing } 2\end{array}$ & $\underline{7 q 11.23}$ & del & del & $\mathrm{x}$ & del & $\mathrm{x}$ & del & del & del & $\mathrm{amp}$ & $\mathrm{x}$ & $7 / 10$ \\
\hline PDXDC1 & $\begin{array}{c}\text { pyridoxal dependent } \\
\text { decarboxylase domain } \\
\text { containing } 1 \\
\end{array}$ & $\underline{16 p 13.11}$ & del & del & $\mathrm{x}$ & del & del & del & $\mathrm{x}$ & del & del & $\mathrm{x}$ & $7 / 10$ \\
\hline MALL & $\begin{array}{l}\text { T cell differentiation } \\
\text { protein like }\end{array}$ & $\underline{2 q 13}$ & del & del & del & del & del & $x$ & del & $\mathrm{x}$ & $x$ & $x$ & $6 / 10$ \\
\hline ANKRD30A & $\begin{array}{c}\text { Ankyrin repeat domain } \\
30 \mathrm{~A} \\
\end{array}$ & $\underline{10 p 11.21}$ & del & del & $\mathrm{x}$ & del & $\mathrm{x}$ & del & $\mathrm{x}$ & del & del & $\mathrm{x}$ & $6 / 10$ \\
\hline PTPN20 & $\begin{array}{l}\text { PTPN20 protein tyrosine } \\
\text { phosphatase, non- } \\
\text { receptor type } 20\end{array}$ & $\underline{10 \mathrm{q} 11.21}$ & del & del & del & $\mathrm{x}$ & del & $\mathrm{x}$ & $x$ & del & del & $\mathrm{x}$ & $6 / 10$ \\
\hline USP22 & $\begin{array}{l}\text { ubiquitin specific } \\
\text { peptidase } 22\end{array}$ & 17p11.2 & $\mathrm{x}$ & del & $\mathrm{x}$ & del & $\mathrm{x}$ & del & del & del & del & $\mathrm{x}$ & $6 / 10$ \\
\hline
\end{tabular}

\section{Discussion}

CGH array is a useful method for detection of DNA copy number alterations among Ewing sarcoma patients. In our patient cohort, srGAP2, RGPD5, NPHP1, GTF2IRD2, PDXDC1 are found as most copy number altered genes. srGAP2 is a member of SLIT-ROBO Rho GTPase activating protein family, which regulates actin dynamics in cell migration, cell differentiation and neuronal migration. The gene is also located in the region 1q. The deletion in 1q regions were observed in previous CGH analysis as well [6]. RGDP5 is a nuclear membrane associated protein and regulates cellular functions through interactions with other proteins. NPHP1 is interacting with Crk associated substrate and functioning in controlling cell division, cell-cell and cell-matrix adhesion signaling. GTF2IRD2 is a transcriptional factor under the control of Retinoblastoma protein. MALL is participating in raft mediated trafficking in endothelial cells. MAL1 interacts with caveolin and localizes in glycolipid or cholesterol enriched membrane rafts. PTPN20 is a member of protein tyrosine phosphatases and involving in actin polymerization. USP22 is an interesting gene and regulates various cellular and organismal processes such as cell proliferation, apoptosis and malignancy. It also deubiquitinates histones $\mathrm{H} 2 \mathrm{~A}$ and $\mathrm{H} 2 \mathrm{~B}$, thereby acting as coactivator. USP22 participates in activation of several oncogenes such as MYC and contributing to stemness in colorectal carcinogenesis as well as epithelial mesenchymal transition in osteosarcoma cell lines. ANKRD30A expressed in epithelial cells and in testis, its altered expression levels is found to be associated with breast cancer. TPTE is PTEN related tyrosine phosphatase and plays role in endocrine signal transduction pathways and in spermatogenic function of testis. CTSE encodes peptidase that involves in antigen processing and maturation of secretory proteins $[7,8]$.

\section{Conclusions}

In conclusion, in our dataset the copy number alterations are mostly found in genes related with cytoskeletal elements, migration and protein trafficking among our patient group. Gene functional studies are required for better understanding the role of these genes in Ewing Sarcoma pathogenesis.

Acknowledgments: This study was financially supported by Association of Turkish Pediatric Oncology Group(TPOG).

\section{References}

1. Balamuth, N.J.; Womer, R.B. Ewing's sarcoma. Lancet Oncol. 2010, 11, 184-192.

2. Delattre, O.; Zucman J.; Melot, T.; Garau, X.S.; Zucker, J.M.; Lenoir, G.M.; Ambros, P.F.; Sheer, D.; TurcCarel, C.; Triche, T.J.; et al. The Ewing family of tumors-A subgroup of small-round-cell tumors defined by specific chimeric transcripts. N. Engl. J. Med. 1994, 331, 294-299. 
3. Burchill, S.A. Ewing's sarcoma: Diagnostic, prognostic, and therapeutic implications of molecular abnormalities. J. Clin. Pathol. 2003, 56, 96-102.

4. Brohl, A.S.; Solomon, D.A.; Chang, W.; Wang, J.; Song, Y.; Sindiri, S.; Patidar, R.; Hurd, L.; Chen, L.; Shern JF.; et al. The Genomic Landscape of the Ewing Sarcoma Family of Tumors Reveals Recurrent STAG2 Mutation. PLoS Genet. 2014, 10, e1004475.

5. Redon, R.; Carter, N.P. Comparative Genomic Hybridization: Microarray design and data interpretation. Methods Mol. Biol. 2009, 529, 37-49.

6. Savola, S.; Klami, A.; Tripathi, A.; Niini, T.; Serra, M.; Picci, P.; Kaski, S.; Zambelli, D.; Scotlandi, K.; Knuutila, S. Combined use of expression and CGH arrays pinpoints novel candidate genes in Ewing sarcoma family of tumors. BMC Cancer 2009, 9, 17.

7. Available online: www.ncbi.nlm.nih.gov/gene (accessed on 1 October 2018).

8. Zhang, D.; Jiang, F.; Wang, X.; Li, G. Downregulation of Ubiquitin-Specific Protease 22 Inhibits Proliferation, Invasion, and Epithelial-Mesenchymal Transition in Osteosarcoma Cells. Oncol. Res. 2017, 25, 763-771.

(C) 2018 by the authors. Licensee MDPI, Basel, Switzerland. This article is an open access article distributed under the terms and conditions of the Creative Commons Attribution (CC BY) license (http://creativecommons.org/licenses/by/4.0/). 